\title{
La gran ola de Kanagawa, configuración morfológica y compositiva de una obra emblemática
}

The great Wave off Kanagawa, morphological and compositive configuration of an emblematic work

\author{
MARÍA ALICIA HERRERA HERNÁNDEZ* \\ Universidad Autónoma de Ciudad Juárez (UACJ) \\ México \\ * alicia.herrera@uacj.mx/alicia.volta@gmail.com \\ (iD) https://orcid.org/0000-0003-2045-4467 \\ d.) https://doi.org/10.52948/ds.v3i2.426
}

Artículo de investigación

Recepción: 20 de noviembre de 2020

Aprobación: 6 de julio de 2021

Cómo citar este artículo:

Herrera Hernández, M. (2021). La gran ola de Kanagawa, configuración morfológica y compositiva de una obra emblemática. Designio, 3(2) 120 - 140

Reconocimiento-SinObraDerivada 4.0 Internacional (CC BY-NC-ND) 


\section{Resumen:}

La gran ola de Kanagawa (1830-1833) es una pieza artística, una imagen que refleja las visiones personales del artista que la crea, aun cuando su confección no esté fundamentalmente intencionada a la funcionalidad del mensaje visual. El propósito de este estudio es identificar las características estéticas y formales de la obra de Katsushika Hokusai (1760-1849), La gran ola de Kanagawa, con la intención de vislumbrar las cualidades que hicieron destacar a esta obra de entre la totalidad de estampas de la serie a la que pertenece. El análisis se realizará por medio de la propuesta metodológica para el análisis de la imagen (fotográfica) de Javier Marzal Felici y comprende el estudio de la imagen a nivel contextual, morfológico y compositivo. El resultado consiste en la visualización de las cualidades estético, formales y configuradoras de la imagen, así como nuevamente exponer la genialidad de esta estampa icónica de la xilografía ukiyo-e

Palabras clave: La gran ola de Kanagawa; Treinta y seis vistas del monte Fuji; Katsushika Hokusai; análisis de la imagen.

\section{Abstract:}

The Great Wave off Kanagawa (1830-1833) is an artistic piece, a picture that reflects the personal vision of the artist that create it, even when its confection is not fundamentally intentional to the visual message functionality. The purpose of this study is to identify the aesthetic and formal characteristics from Katsushika Hokusai (1760-1849) work, The Great Wave off Kanagawa, with the intention of glimpse the qualities that highlight this work between the whole print from the series where it belongs. The analysis is going to be doing via the methodological purpose for the image analysis (photographical) from Javier Marzal Felici and understands the picture study at a contextual, morphological and compositive level. The result consists in the visualization of the aesthetic, formals and configurator qualities of the picture, as well as an exposition of the genius of this iconic print of the ukiyo-e woodcut.

Keywords: The Great Wave off Kanagawa; Thirty-six Views of Mount Fuji; Katsushika Hokusai; image analysis. 


\section{Introducción}

La gran ola de Kanagawa es una pieza artística, una ilustración estampada en grabado xilográfico, aun cuando su confección no esté fundamentalmente intencionada a la funcionalidad del mensaje visual al ser una imagen que refleja las visiones personales del artista que la crea. Es propósito de este estudio el análisis a profundidad de la obra a través de algunos de los conceptos pertenecientes a los fundamentos del diseño también usados en el análisis de la imagen con la intención de vislumbrar sus cualidades estético-formales que la hicieron destacar a La gran ola de Kanagawa de entre la totalidad de 46 piezas de una serie a la cual pertenece titulada Treinta y seis vistas del monte Fuji.

Dentro de este orden de ideas, se propone vislumbrar y estudiar las características estético-formales de la obra La gran ola de Kanagawa a través de los principales conceptos de los fundamentos del diseño, con la finalidad de abrir camino y complementar otros estudios sobre la imagen. A partir de esto se presentan esencialmente las siguientes interrogantes de investigación a resolver: ¿Cuáles son las características estéticas y visuales de la obra de Hokusai La gran ola de Kanagawa? ¿Cuál es el color dominante y su(s) significado(s) dentro de la misma?

Katsushika Hokusai (1760-1849) es el artista de origen japonés más famoso dentro y fuera de su país. Es usual encontrarse y reconocer una representación de La gran ola de Kanagawa (1830-1833) sin ser especialistas en arte. Esta estampa xilográfica de Hokusai se ha convertido en la más universal de todos los tiempos. Esta obra ha alcanzado un distintivo interés. En palabras de Almazán (2019):

Es la más famosa de las obras de arte de Japón, hasta llegar a convertirse en un ícono del país del sol naciente. Esta estampa fue una de las más influyentes del japonismo, la oleada de arte nipón que inundó Occidente en el último tercio del siglo XIX, efecto que sigue vigente hasta nuestros día. (p. 124)

El recorrido por las sendas del arte de Hokusai es excepcional, cuenta con miles de obras entre ellas estampas de casi todos los géneros en las ukiyo-e, al igual que ilustraciones y dibujos que dan origen al manga entre otras particularidades. Sin profundizar en esto, únicamente con una contemplación atenta a la serie Treinta y seis vistas del monte Fuji, a la que pertenece La gran ola de Kanagawa, nos presenta numerosas y diversas estampas de Hokusai. Como acertadamente señala el estudioso 
de la estampa japonesa David Almazán (2019), simplemente esta serie nos muestra un infinito catálogo de las posibilidades compositivas en la diversa y basta obra del maestro de la estampa japonesa.

Esta serie es esplendida para ahondar en la obra de Hokusai y del grabado ukiyo-e, manifestación cultural genuinamente japonesa que refleja los gustos y cotidianidad de las clases medias urbanas del periodo Edo (1615-1868). El término proviene en su origen de los textos budistas ukiyo-e, que significa literalmente "imágenes del mundo flotante" o "imágenes del mundo efímero o mundo que fluye" y deriva de la idea budista del carácter efímero e ilusorio de la existencia terrenal que es necesario trascender para alcanzar el verdadero conocimiento. Sin embargo, en el periodo Edo "este concepto se interpretó como las diversiones de la población urbana en las casas del té y en los barrios del placer; en el teatro kabuki y en los torneos de sumo" (Saracho, Martín, y Gómez, 2013, p. 205); en adición "las clases populares de las ciudades japonesas se sintieron más atraídas por las diversiones mundanas que por la salvación eterna e hicieron suyo el término ukiyo para definir su cultura" (Almazán, 2019, p.7).

El término se compone de tres ideogramas: Uki, u, que aporta el significado de pasajero, algo que flota y se desvanece, yo, $\mathrm{u}$, que significa mundo, y e, $\mathrm{u}$, que incorpora el sentido de representación o imagen. De esta combinación de ideogramas se desprende la interpretación generalizada de "imágenes del mundo flotante" [...] los artistas buscan expresar el carácter efímero de los placeres mundanos, pero sin las connotaciones negativas que se han desarrollado en Occidente debido a la influencia del cristianismo y la arraigada creencia en una vida más allá de la muerte. (García, 2013, p. 99)

En síntesis, "llamaremos 'xilografía Ukiyo-e' a aquella producción estéticosimbólica que hace uso de la técnica de impresión xilográfica y que se desarrolla y florece como parte del complejo cultural chōnin" (García Rodríguez, 2005, p. 39). Durante el periodo de la ciudad Edo -periodo artístico de mayor esplendor de este formato que se desarrolló en la ciudad del mismo nombre: Edo, la actual Tokio (1660 - 1868)- Japón estuvo regido por los samuráis del clan Tokugawa.

Con Japón unificado desde inicios del siglo XVI, los Tokugawa instauraron una estable dinastía, un rígido sistema de clases sociales de fuerte control social, dominado por samuráis (intocables y destacados) y formado por los agricultores, los artesanos, y los comerciantes (grupos marginales). Según Almazán (2019): 
Comerciantes y artesanos, la gente de la ciudad o chõnin, como se llamaban, tenían su propia cultura, muy alejada de los poderosos. La "alta cultura" estaba al servicio de los grandes señores feudales y los templos. Sin libertad ni movilidad social, el mundo flotante era al mismo tiempo un espacio en el que disfrutar de los placeres cotidianos y un laberinto en el que escapar de las imposiciones sociales de los gobernantes samuráis, los cuales, por cierto, o tenían problemas en permitir el ocio siempre y cuando no interfiriera en la política. Barrios de placer, como el célebre Yoshiwara, casas de té, restaurantes y teatros eran los lugares de esparcimiento de los habitantes de Edo, que tenían sus propios artistas y un sistema de producción de imágenes asequibles: el grabado ukiyo-e. (p. 8)

Para entender esta y otras obras artísticas, así como a las imágenes, es sumamente importante conocer sobre el contexto: en específico esta manifestación artística del periodo Edo, a la cual pertenece la estampa La gran ola de Kanagawa. Lo anterior es reflejo de la cotidianidad y diario vivir de sus ciudadanos, en la multiplicidad de géneros dentro de las estampas ukiyo-e así como en específico la de paisaje (fukei-ga) género al que pertenece la serie Treinta y seis vistas del monte Fuji, así como la obra en la que se centra el presente trabajo; representaciones que nos acercan y permiten vislumbrar como era la vida en aquellos días en ese espacio geográfico. Son testimonio de una sociedad con su particular ideología y filosofía; además de una declaración de su religiosidad y estilo de vida. Imágenes que nos invitan a observarlas no solo por todas las características mencionadas anteriormente, sino también por sus cualidades estético formales de las cuales hablaremos a continuación.

\section{Metodología}

La metodología que se llevó a cabo en la investigación fue basada en un enfoque cualitativo de alcance exploratorio debido a que inicialmente contamos con información general respecto a un problema poco conocido y anteriormente poco abordado como lo es vislumbrar las características estético-formales de la obra La gran ola de Kanagawa, a través de los principales conceptos de los fundamentos del diseño (lenguaje visual), con la finalidad de complementar otros estudios sobre esta mundialmente conocida imagen. 
El planteamiento metodológico de la investigación comienza con la revisión de fuentes bibliográficas, documentos relacionados con el tema, como libros, artículos científicos de diversas bases de datos universitarias; asimismo, análisis de ilustraciones, estampas y obras artísticas del pintor y grabador japonés Katsushika Hokusai. De igual forma, el análisis de ilustraciones y trabajo de artistas internacionales que en la actualidad retomen la xilografía del periodo Edo.

Todas las variables son en sí un aporte al tema y se contemplarán desde una perspectiva global, sin dejar de lado el hilo conductor de la investigación. La finalidad es comprender sobre esta práctica de visualidad y las aportaciones en la gramática del lenguaje visual, para lograr hacer un análisis de los elementos visuales (estéticoformales) en la estampa xilográfica del género de paisaje La gran ola de Kanagawa, y con esto no llegar a generalidades sino de una especificidad observable.

Se realizó un cotejo de todos los datos obtenidos y problemas planteados a lo largo de la investigación para lograr una interpretación profunda que nutra el tema, hablando específicamente de factores como lo son la observación directa. Esta última se realizará a través de una matriz tomada del modelo de análisis de la imagen (fotográfica) del Dr. Javier Marzal Felici, como instrumento de investigación.

La selección de esta matriz corresponde a que se comparte la intención del investigador que la propone (Javier Marzal Felici) de la necesidad de un análisis de la imagen desplegado a través del examen riguroso de las condiciones de producción, recepción y del propio estudio de la materialidad de la obra (ya sea pictórica, xilográfica, fotográfica o de técnica múltiple, etc.).

El análisis del texto visual que se siguió en la presente investigación sigue la propuesta de Javier Marzal Felici (2005); se funda en la diferenciación de una serie de niveles "desde la estricta materialidad de la obra y su relación con el contexto histórico- cultural, hasta un nivel interpretativo" (p. 55). El nivel interpretativo no se realiza en esta investigación, pues no es parte de la finalidad de la misma. Los niveles estudiados son: nivel contextual, morfológico y compositivo.

\section{Resultados y discusión}

En lo que corresponde al nivel contextual, conscientes del problema de la interpretación, que como investigadores en el análisis de la imagen es muy común proyectar durante este estudio una carga considerable de gustos, convicciones y prejuicios. En el presente trabajo se opta por el empleo del análisis a nivel contextual 
de la propuesta metodológica de Marzal Felici (2005) como antídoto a este posible condicionamiento. Para el desarrollo de este primer nivel es necesario recabar:

La información necesaria sobre la(s) técnicas(s) empleada(s), el autor, el momento histórico del que data la imagen, en movimiento artístico o escuela [...] a la que pertenece, así como la búsqueda de otros estudios críticos sobre en la obra en la que se enmarca la imagen que pretendemos analizar. La culminación de este primer nivel del análisis trata de mejorar nuestra competencia lectora. (pp. 58-59)

Cabe señalar que la propuesta del Dr. Marzal Felici fue diseñada en específico para el análisis de la imagen fotográfica, pero al observarla con detenimiento se encontró viable la aplicación de la misma en imágenes que pertenecen a otra técnica de realización como la pictórica y en este caso específico a la xilografía. El método original está pensado específicamente para el análisis de imágenes de la mayor complejidad textual posible, en general, "fotografías de autor". Por este motivo el análisis se vuelve viable al aplicarlo en imágenes que derivan de otra técnica diferente a la fotográfica. Regularmente, la información necesaria para realizar el nivel contextual de este tipo de imágenes se encuentra a disposición del lector, en los libros y catálogos, y hoy en día suele ser más frecuente encontrarla en la web.

En este primer nivel se debe esclarecer la información general sobre la imagen, título de la imagen (u obra), este es esencial puesto que suele afianzar la intención inicial en la representación estudiada: "el sentido desde la perspectiva de la instancia del autor empírico" (Marzal, 2005, pp. 59-60). De igual forma es indispensable establecer otros datos del autor como su nacionalidad, o el año de realización de la imagen, su procedencia, técnica, movimiento artístico, escuela, entre otros. 
Figura 1. Nivel contextual, propuesta de Marzal

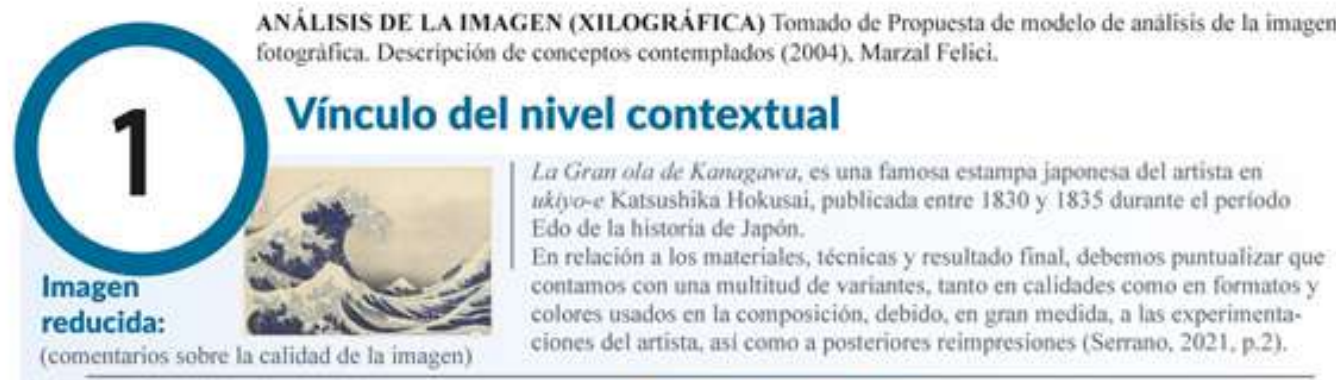

\section{DATOS GENERALES}

Título: La gran ola de Kanagava, "Heva como titulo original en japonés Kanagana oki mami-ura/ cuya traducción varia segün la fuente consultada siendo, por ejemplo, The great wave off shore of Kanagawa (La grain ola frente a la casta de Kanagawa) para la Biblioteca del Congreso de los Estados Unidos, Under the Wiave off Kanoganva (Bajo la ola de Kanazawaj para el British Museum y el Metropolitan Museum of Art de Nueva York, L'an de la vague an larye de Kanagava (El anoo de la ola frente a Kanagawa) para la Bibliothcque nationale de France o Bajo la ola de Kanagana para el Museo Nacional d'Art de Catalunya. Algunas fuentes digitales indican que la traducción literal correspondiente es Bajo tma ola en altamar en Kanagonva. Popularmente se conoce a esta obra, en sus diferentes traducciones, como: $L a$ gran ela de Kanagawa, La graw ola o simplemente La ofa" (Serrano, 2021, p.1).

\begin{tabular}{c|c|c} 
Autor: & $\begin{array}{c}\text { Katsushika Hokusai } \\
(1760-1849)\end{array}$ & Nacionalidad: Juponés
\end{tabular}

Año El periodo cronológico en el que podemos demarcar la realización de esta obra varia según las fuentes consultadas; de igual forna es importante contemplar que esta pieza (La gran ola de Kamagava) pertenece a la serie Treinta y seis vistar del monte Fuii, "Se puede estimar qué, la serie de estampas, seria encaryada, concebida y publicada (en tres volùmenes) entre 1826 y 1833, vièndose ampliada de las 36 originalmente proyectadas a 46 gracias al gran éxito cosechado" (Serrano, 2021, p.1).

\begin{tabular}{|c|c|c|}
\hline Procedencia: Japón & Género: Ukjyo-et & Género 2: Fukei-ga (paisaje) \\
\hline \multicolumn{3}{|c|}{ PARÁMETROS TÉCNICOS } \\
\hline B/N / Color: Color & Formato: Altura: 25.7 centimetros & 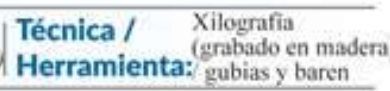 \\
\hline Soporte: Papel de arroz & $\begin{array}{r}\text { Representación de la cotidianida } \\
\text { Objetivo: Edo (1603-1868), "ípoca en la q } \\
\text { lúdico, pedagógico y mediático" }\end{array}$ & $\begin{array}{l}\text { ad de la sociedad chänin del periodo } \\
\text { que nacieron como un elemento } \\
\text { "(Koyama-Richard, 2014, pärr. 1). }\end{array}$ \\
\hline
\end{tabular}

\section{Otras Informaciones:}

Al maestro de la estampa japonesa Hozumi Harunobu también conocido como Suzuki Harunobu (1717-1770) quien nació en las proximidades del periodo Edo. Es a quien se le atribuye alrededor de los años 1760-1765 la creación de la técnica nikishi-e ( estampa brocada) la cual es un tipo de impresión xilogrífica japonesa con la caracteristica principal de la implementación de múltiples colores y principalmente empleada en el ukivo-e.

En los inicios de la xilografia ukjob-e, la mayoria de grabados eran en blanco y negro, o coloreados a mano o con la adición de uno o dos tacos de tinta de color. Una estampa nishikj-e se crea grabando un taco o plancha de madera diferente para cada color. Usualmente el material que se utiliza para esta matriz (taco o plancha) es una madera de un tipo de cerezo llamada yamasukura y para tallar o grabar esta matriz se emplean unas herramientas con apariencia de cuchillas cortas llamadas gubias (de mango distinto de las utilizadas por los artistas occidentales) (Gareia Sánchez-Migallón, 2013) para crear los blancos de la imagen con la extracción del material. Una vez finalizado el gubiado de cada una de las matrices para cada color de la estampa, posteriormente se impregna una matriz con tinta "de base actoosa y de colores vegetales que se aplican con brochas sobre papeles washi muy delicados y finos, casi traslícidos, de fibra larga y colas vegetales" (Garcia Sánchez-Migallón, 2013,p. 99), Se comienza con la matriz que estampara el color más oscuro, usualmente el azul Prusia; se utiliza como gufa donde posteriormente caerán el resto de los colores.

Esta la estampación es manual con baren, lo que "proporciona sutiles difuminados, variaciones de intensidad" (Garcia Sánchez-Migallón, 2013. p. 99) asi como lineas muy finas, En este contexto de innovaciones técnicas surge un procedimiento de degradados de los colores que recibe el nombre de bokashi. Asi, en suma, se repite el proceso con cada una de las matrices talladas destinadas para cada color, finalizando nuevamente con el color oscuro para resaltar las líneas dentro de la estampa.

Fuente: elaboración propia. 
ANÁLISIS DE LA IMAGEN (XILOGRAFICA) Tomado de Propuesta de modelo de análisis de la imagen fotografica. Descripción de conceptos contemplados (2004). Marzal Felici.

\section{Otras Informaciones:}

El estilo y estética reflejados en la estampa japonesa clásica son el resultado de una tradición de más de cuatrocientos antos. En lo que respecta a la producción de ukivo-e es un trabajo de equipo integrado de cuatro personas: el artista, el grabador, el impresor, y el editor (Mariac, 2012). El editor (hanmoto) le cncarga al artista (eshi) un proyecto y éste realiza un dibujo o boceto preliminar en tinta negra (hanshita-e). Si el dibujo es aprobado por el editor, el grabador (horishi) talla la plancla con el dibujo en madera de cerezo. Seguidamente el impresor (surishi) selecciona los tintes. vegetales y los colores apropiados para su estampación (Garcia Sánchez-Migallón, 2013). "Algunos efectos y técnicas especiales requieren más tiempo y alteran el proceso ligeramente, pero por lo general, en la cpoca de la que datan los grabados, se realizaban unas 200 impresiones de cada plancha al dia y el trabajo se acababa en unas dos semanas" (Garcia Sánchez-Migallón, 2013, p. 99).

En resumen, la técnića xilografíca surge como medio de expresión del arte civil. Estas estampas resultaban accesibles para muchas personas por gusto en la pintura, pero cuya cconomia no les permitia la compra de obras originales. Los whijo-e se reproducian de forma masiva y a bajo precio, los temas principales hacen referencia a ta vida de la ciudad, lo cotidiano, pero también representan escenas de flores y de animales, estampas de cortesanas y de geishus, escenas de teatro, temas eróticos, etc. Se trata de una técnica compleja, además de realizar el dibujo inicial, se debe realizar una matriz para cada tinta de color distinto e imprimir la estampa tantas veces como colores tenga. Los materiales que se emplean comúnmente para la elaboración de una estampa son: madera de cerezo, pigmentos de origen vegetal de facil dilución en agua, tinta sumi para el negro, pasta nori, hecha de harina de arroz utilizada como pegamento y papel.
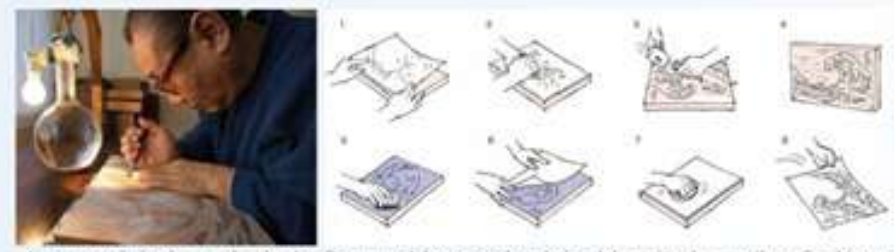

Aricsano tratujando una plancha de Resumen del proceso de trabajo claboración de una valografia ufino-s

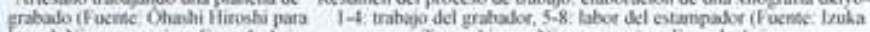
la web Nippon comi en Esos \& Asia. Isup onhi pura Nirgoin. com) en Eaco de Asia.

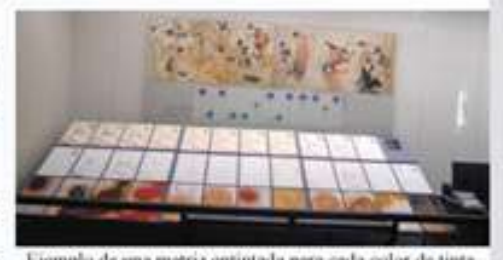

Ejemple de una makriz entintada para cada color de tinte. fotoperafia proporcionalo por ta Dra. Hortcrasia Minguez

\section{DATOS BIOGRÁFICOSY CRÍTICOS}

Hechos biográficos relevantes:

- Dibujante y grabador japonés.

- Nacido en Edo (actual Tokio) en 1760.

- Discipulo de la escuela thijo- $c$.

- De nin̂o fue adoptado por los Nakajima (familia de gran tradición artistica).

- A los 18 años se convirtió en aprendiz de un destaciado maestro de ukijo-e ey tras la muerte de su maestro, inició su carrera e independencia artistica donde realizó tanto grabados como ilustraciones.

- 1806 concentró su atención en la representación de paisajes y eseenas hístóricas

- Despuls de la muerte de su hijo mayor se introdujo, en un género más comercial como el libro de ilustraciones.

- Dentro de las que destacan las Treinta y seis vistas del monte Fuji

- Fallece en 1849 en la ciudad de Edo.

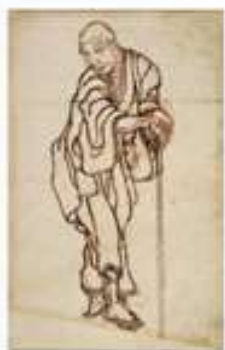

Tutomerima Ristashido Hodicen. an Hobonart

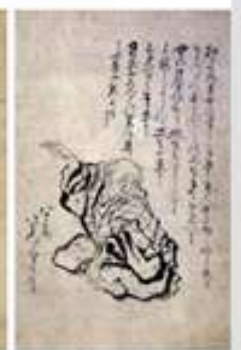

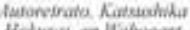
Hidusan en Hahmoart

Fuente: elaboración propia. 
Asimismo, en este nivel es de suma importancia integrar otros datos como: tamaño o dimensiones de la imagen u obra, si tiene un formato en específico, definir el nombre del mismo, así como el tipo de soporte (tipo de papel, tipo de lienzo) y las especificaciones técnicas de la imagen (fotografía a blanco y negro, estampa xilográfica, óleo, etc.). Finalmente, en este nivel es indispensable precisar de algunos datos sobre la bibliografía del autor de la imagen. Incluso de documentos oficiales o críticos realizados por especialistas en torno a este y su obra. De esta forma es posible incorporar al análisis información sobre las condiciones de producción y exhibición -pues en el caso particular de la imagen xilográfica-; al tratarse de una edición de múltiples estampas de una sola pieza, es posible localizar expuesta la misma imagen en "original" en diferentes museos. Si embargo, no hay que perder de vista la siguiente declaración de los autores de este método, por consiguiente:

Estas informaciones tienen un carácter meramente orientativo, ya que en el análisis de la imagen es conveniente distinguir con claridad entre el autor "empírico" y la instancia "enunciativa". El autor empírico es una instancia ajena a la materialidad del texto (visual) analizado, cuya intencionalidad escapa a nuestro saber, mientras que la enunciación se refiere a las huellas textuales que se pueden hallar en la propia imagen. (Marzal, 2005, p. 61)

En la segunda etapa del análisis es el nivel morfológico, respecto a este se obedecen las premisas trazadas por distintos autores, diversas entre sí, dado que se abordan conceptos de apariencia simple, pero de considerable complejidad, como el punto, la línea, el plano, el espacio, la escala, el color, entre otros los cuales participan de una condición morfológica, dinámica, de dimensión y compositiva (Marzal, 2005). En este nivel se desea adquirir una perspectiva descriptiva, aun cuando comienzan a manifestarse apreciaciones de naturaleza valorativa. Es esencial tener conocimiento de que todo análisis ineludiblemente contiene una actividad proyectiva.

Se trata de comenzar con una descripción formal de la imagen, tratando de deducir cual[es] ha[n] sido la[s] técnica[s] empleada[s]: parámetros como el punto [...], la línea (rectas, curvas, oblicuas, etc.), el plano (distinción de planos en la imagen), el espacio, la escala (tamaño de los personajes [...] la forma (geometría de las formas en la imagen), textura, nitidez de la imagen, contraste, tonalidad [...], características de la iluminación (direcciones de la luz, natural/ artificial, dura/suave, etc.). El conjunto de aspectos tratados nos permitirá señalar si la imagen es figurativa/abstracta, simple/compleja, monosémica/ polisémica, original/redundante, etc. (p. 61) 
ANÁLISIS DE LA IMAGEN (XILOGRÁFICA) Tomado de Propuesta de modelo de analisis de la imagen fotografica. Descripción de conceptos contemplados (2004), Marzal Felici.

\section{Nivel morfológico}

Descripción del motivo xilográfico:

"La gran ola de Kanagonsa es la más famosa de las obras de arte de Japon, hasta llegar a convertirse en feono del Pais del Sol Naciente. Esta estampa fue una de las más influyentes del Japonismo, la oleada de arte nipón que inundó Occidente e el último tercio del siglo XIX. Su impacto sigue vigente. [...] La obra es tan famosa que se conoce popularmente como La gram ola, o simplemente La ola. Por su universalidad ha surgido esta tendencia a simplificar su titulo. Siendo estrictos, la traducción literal del titulo original Kanagawa oki nami ura deberia ser Tras la gran ola de Kanaganva. Muchos estudios sobre las Treinta y seis vistas del monte Fuji comienzan con esta estampa, que no fue la primera, ni nunca se pretendió que ocupara un lugar preeminente entre toda, si bien su original e impactante diseño, tiene con justicia la capacidad de representar toda la obra de Hokusai" (Almazán, pp. 124, 2019).

En lo que corresponde a sus cualidades formales "la forma triangular del Fuji se inscribe en un circulo semiabierto que configura la cresta de la ola gigante. El Fuji nunca se habia visto asi hasta entonces, La ola, dibujada con una precisión asombrosa, expresa la fuerza de y violencia de la naturaleza. Hasta el propio Fuji parece insignificante bajo la gran ola. No estamos en alta mar y la costa no esta muy lejana, pero la fuerza del oleaje es extrema., pues las aguas del océano Pacifico en esta región no son dóciles. Las barcazas son del tipo ashiokuribume, de poco calado y guiadas por una pertiga, de las que se empleaban fundamentaimente para el transporte del pescado fresco"- (Almazin, pp. 124- 125. $2019)$. Punto: Es la unidad más simple, imeduciblemente minima, de comunicación visual. En la nuturaleza, las ciatrado (Dondis, 0.28, 1992).

Como base de la configuración plástica es de forma redonda a ovalada (orgánico). El autor no deposita color sobre el punto, pues mantiene el blanco del papel. El conjuto de puntos empleados en la composición de la obra artística se encuentra situados sobre el mar y el cielo y representan de forma figunativa la espuma de las olas del mar. Los puntos son de tamanos variados en algunas partes están más concentrados, asi como también se puede observar una dispersión progresiva de centro a exterior del cümulo de puntos. Siguen una cierta dirección y muestran el camino de descenso de la ola y como abatirá con el mar. Producen sensaciones de tensión y dirección.
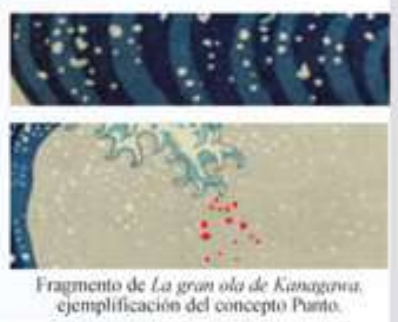

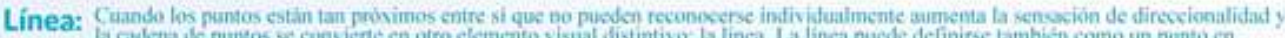

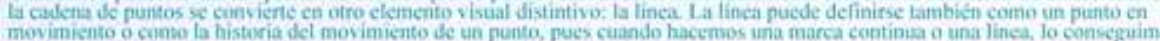
movimicnto o cono la historia det movimiento se us punto, pots cuando hacensos una marca coptibia o una linea, lo conseguimos quede registrada (Dondis, pp. 56-57, 1992)

Por su parte la Línea es la encargada de "escribir" una forma. Kandinsky la define como la huella de un punto en movimiento y partiendo de este concepto se identifica el trazo en la obra de Hokusai. En la Gran ola de Kanagava; la linea cumple dos funciones: como elemento configurador o estructural y como elemento expresivo.

En su función estructuradora se puede identificar cuando la línea es utiliza para configurar una forma determinada dentro de la composición de la obra como es la fabricación de elementos figurativos formales como los son las olas; la montaña, las barcas, etcétera.

Especificamente en esta pieza la linea es un instrumento de gran versatilidad y adopta por variedad de grosor todas sus variantes en punto muy delgado casi imperceptibles a la vista, pero presentes en la obra. Respecto a la forma de la línea (trazo) mantiene una apariencia orgánica y continua; finalmente el coloe en el trazo se mantiene en el tono azul de Prusia de manera uniforme.

El empleo de la linea como clemento expresivo se asocia de lo figurativo de un trazo delgado continuo, lizo (sin textura visual) y uniforme a una linea tranquila, sublime, pacifica y aplacible -diferente al elemento expresivo del punto que es dinámico y desastroso-

\section{Tipos de líneas contenidas en la obra:}

Líncas oblicuas: a partir de su relación con los cuerpos en caída por la condición inestable que ticnen.

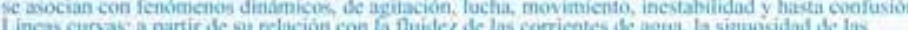

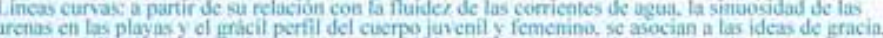
cencanto, delicalez, movimiento, ritmo, suavidad: su caricter dependera del tipo de curva yus we trace. Partiendo de este par de categorias dentro de la tipologia de la linea asociamos el elemento expresivo de la misma dentro de la Gran ola de Kanagawa con tendencia a enunciar una dicotomia que por uma parte manifiesta agitación, lucha e inestabilidad y por otra expresa encinto suavidad y delicadeza.

La línea define el contorno de las cosas se debe tener en cuenta que estas cualidades aqui relacionadas y atribuidas a las diferentes lineas, no operan espontaneamente, no funcionan mecánicamente, sino que estain fuertemente condicionadas por el entorno en el que se hallan y con el cual existe en constante interacción.

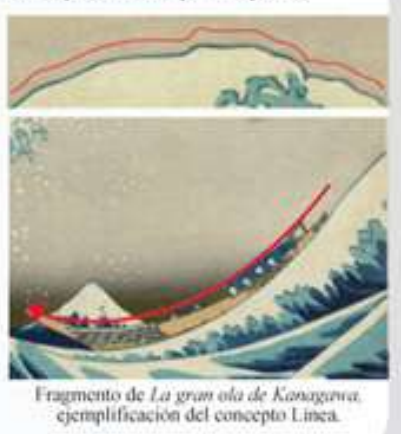

Fuente: elaboración propia. 
ANẢLISIS DE LA IMAgEv (XILOGRÁFICA) Tomado de Propuesta de modelo de análisis de la imagen fotografica. Descripción de conceptos contemplados (2004). Marzal Felici.

\section{Plano(s) - Espacio:}

Las superficies pueden ser verticales, horizoutales, inclinadis, cóocavas, boavesas, forcida. distorsonada, curvada, angulat, cte.

El plano en el espacio compositivo de la Gran ola de Kanagawa es presentado en areas con formas determinadas (largo y ancho) que percibimos por contraste de figura y fondo y escasamente por un contomo lineal.

Los planos empleados en la obra son de tipo irregular, pues estas superficies son de formas muy variadas y presentan notables diferencias en la medida de sus lados

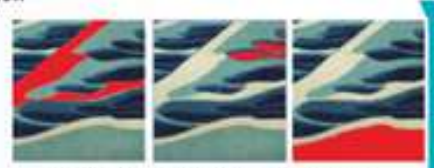
Frapencalo de La yran ola de Kanaegra cjemplifinacion del eonsepto Plans.

y àngulos, asi como sus contomos son irregulares. Todos estos en conjunto producen la sensación de inestabilidad y movimiento, Asi mismo es notable una yuxtaposición de planos que crea sensación de cercania - lejania.

De igual forma, el artista maneja los planos para representar variaciones de luminosidad en superficie del mar, así como para producir efectos de luz y sombra en las olas.

Forma:

- Aunque es visto desde el fondo, el monte Fuji es la figura central de la obra. Ya que en Japón es considerado sagrado que a su vez es un simbolo de belleza e identidad nacional.

- En esta famosa estampa lo podemos observar en una pequet̃a dimensión en comparación al área total de la estampa, en último plano, de color azul Prusia con el cráter nevido representado con el color blanco del papel.

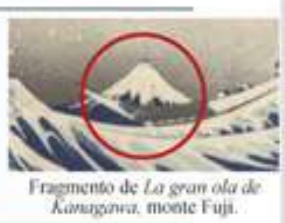

- La escena muestra tres oshiokuri-bune, barcazas rápidas que se utilizaban para transportar el pescado desde las peninsulas de lza y Bósó hasta los mercados de la bahia de Edo.

- Como lo indica el nombre de la obra, los barcos se encuentran en Kanagawa, con Tokio (Edo) al norte, el relieve del Fuji al noroeste, la bahia de Sagami al sur y la bahia de Tokio al este. Los barcos, con orientación al suroeste, regresan de la capital.

- Dentro de los botes hay ocho remeros por embarcación, que se aferran a sus remos.

- Hay dos pasajeros más en el frente de cada barco, por lo que en la imagen bay un total de treinta hombres. generalmente entre 12 y 15 metros de lango, y si se toma en cuenta que Hokusai redujo la escala vertical en un $30 \%$, 58 ilega a la conclusión de que la ola tiene entre 10 y 12 metros de altura.

- Las cosas hechas por el hombre son efimerns, representado por los barcos arrastrados por la ola gigante, y el sintoismo, donde la naturaleza es omnipotente (la ola).

- El mar es el elemento dominante de la composición, que se basa en la forma de una ola, la cual se extiende y domina toda la escena antes de caer. En este momento la ola hace una espinal perfecta cuyo centro da la posibilidad de ver al monte Fuji al fondo.

Textura:

Fn la obra se aprecia texfura ópticu (visual); por medio de ella el autor fe imprime realismo a la pieza.

La textura visual de esta estampa le da forma y volumen a los planos que forman las olas del mar: se pueden observar principalmente tres tipos de texturas: lineal de planos que crean las luces y sobras en la ola, asi como un efecto de profundidad: de tipo puntillismo: la cual representa la espuma de las olas; $y$ una de tipo espiral (en relieve): plano superior de color celeste donde se concentra la mayoría de la espuma.

Nitidez de la imagen: La imagen es muy clara y nitida, el observador puede fäcilmente apreciar los detalles en la imagen.
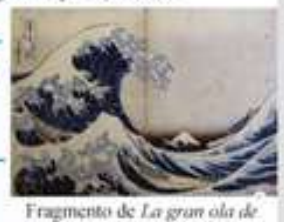
hamagenara representación det mar

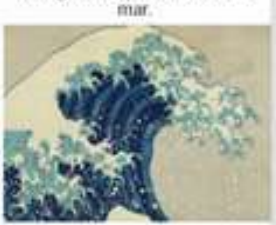

Fragmento de La snam nla de

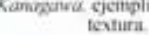

\section{lluminación:}

No solamente se limita a la representación de la luz y su opuesto (la sombra)

En la obra se puede observar luz natural (al amanecer) la cual permite la aparición de sombras color azul Prusia en las olas las cuales a su vez revelan la aplicación de detalle, el color de los elementos y la textura visual en la representación del mar.

El paisaje parece representar la luz de una mañana invernal de cielo nublado en tono grisaceo, no obstante, la pieza pertenece a la luminosidad por sus tonos vibrantes. Claro uso de luces y sombras; olas que esconden y a su vez revelan. Hokusai representa lo que podemos Ilamar sombra en este paisaje con el azul Prusia más saturado de su paleta de color. La luz aparenta aparecer desde el cielo en un ángulo que podria estar ubicado a partir de los $110^{\circ}$ pues esta luz es evidente en la blanca espuma del mar.

Fuente: elaboración propia. 
ANÁLISIS DE LA IMAGEN (XILOGRÁFICA) Tomado de Propuesta de modelo de análísis de la imagen fotografica. Descripción de conceptos contemplados (2004), Marzal Felici.

\section{Tonalidad / B/N - Color:}

El monte Fuji:Azul y blance

Los barcos: Amarillo Paja

El cielo: Degradado Naranja claro, Gris.

"El color oscuro en el cielo alrededor del Fuji probablemente indica que la pintura tiene lugar temprano por la mañana, con el sol saliendo detrás de nosotros en el este, comenzando a iluminar Fuji cubierto de nieve, todavia envuelto en oscuridad. mientras que el cielo más arriba tiene un resplandor dorado que refleja la luz del sol'(Cartwright, 2007, p. 122) (Traducción propia).

El mar (ola): En tres tonos de azul, el Prusia saturado que da la profundidad del mar, azul cielo para sombrear la espuma que está representada en color blanco del papel.

El color en general dentro de La Gran Ola de Kanagawa mantiene una armonia en colores relacionados por analogia (de tonalidades en azul) que se obtiene por colores contiguos en el circulo de color que propician a la semejanza del uno con el otro. En una gama cromática fria, que nos puede indicar (ademats de la representación de la nieve en el cráter del Monte Fuji) que la imagen fue representada durante una temporada invernal, y en lo que parece ser de madrugada.

Segùn Eva Heller (2008) en el titulo Psicologia del Color, menciona, "ningún color carece de significado. El efecto de cada color está determinado por su contexto, es decir, por la conexión de significados, en cual percibimos el color" (p.18), El color azul seguin Heller, es el color de la divinidad, en analogia con el cielo, el color de lo etemo. "La experiencia cotidiana al arul en el color de todo lo que deseamos que permanezca, de todo lo que debe durar eternamente" ( $(p, 23)$. En la misma tesitura, Heller (2008) lo describe como el color de la ilusión de espacio, ya que, en contraposición con colores calidos, un color parece más lejano y distante en cuanto más frio es. $\alpha$ A sociamos colores a las distancias porque los colores cambian con la distancia... En la lejania todos los colores parecen turbios y azulados, debido a las capas de aire que los cubrenw. (p.24).

lncluso un degradado (gradación) de azul intenso a azul pálido produce un efecto perspectivista: el azul claro queda opticamente atrís.

Cuántos más grados de azul vemos en cielo entre azul claro y el azul obscuro, más lejos alcanza nuestra vista. Los pintores Ilaman a este efecto "perspectiva aérea". La regla es que los colores intensos parecen estar más cerca que los pálidos. Los pintores paisajistas lo saben, pues en sus cuadros el azul del ciclo es mis profundo arriba que abajo.

De la palabra italiana del azul ultramarino, $\mathrm{I}$ azzurro proviene el término Lasur, qué es como se nombra en alemán a las "pinturas transparentes". Veamos el agua y el aire de color azul, aunque no son realmente azules.

Un recipiente de vidrio no contiene color cuando dentro de el hay aire, y lo mismo ocurre cuando se llena de agua. Pero cuando más profundo es un lago, más azul se muestra el agua. Con la profundidad llega un momento en que todos los colores desapareeen en azul.

"De igual forma el color de la lejania y del anhelo, el azul es color de lo irreal, e incluso de la ilusión y el espejismo" (Heller, 2008, p.26).

El azul es el color más frio. El origen de que se considere un color frio radica en la experiencia: nuestra picl se pone azul con el frio, incluso los labios torman color azul y el hielo y la nieve muestran tonos azulados. El azul es color de la sombra. desde 1830, los impresionistas empezaron a representar las cosas sin sus colores reales, disolviéndolas en colores de la luz las antiguas sombras pardas desaparecieron de la pintura (Heller, 2008, p.27) En la pintura moderma, las sombras ya no son pardas, son azules.

Fernado Parodi (2002) con un enfoque más oriental en su titulo: La cromosemiótica, el significado del color en la comunicación visual. Define al color azul como el color más inmaterial e indefinido. Metafisico.

En el budismo tibetano es el color de la sabiduria trascendente y la potencialidad; al igual que la vacuidad. $\alpha$ Es el color def yang y tiene significado bienhechon: (Parodi, 2002, p.52).

Finalmente, según Thompson (s.f.) según los colores ceremoniales y tradicionales japoneses, existe algo similar a una paleta de color para cada mes del atho. En esie caso azul profundo del mar coincide con un de los colores asignados para el mes de diciembre (azul profundo y lavanda) que la cultura japonesa intimamente relaciona con la naturaleza, aspecto que nos permite suponer que el paisaje es tomado de la temporada invernal y por esto se le asignan estos colores al mes de diciembre.

\section{REFLEXIÓN GENERAL}

De esta forma el aporte expresivo de las líneas, en este caso, se suma al resto de los elementos que integran el sistema para construir el significado del contenido total de la obra. El nombre o título de la obra, el tema o asunto, los materiales y téenicas por un lado y las condiciones subjetivas del autor actúan como determinantes del significado para cada espectador.

Independientemente de estos caracteres o asociaciones psicolögicas que la tradición y la experiencia social han convertido en convencionalismos más o menos aceptados, existe siempre la posibilidad de buscar nuevas interpretaciones tanto por parte del artista como del espectador, de innovar, de modificar este código visual de acuerdo con las transformaciones que haya sufrido la sociedad en su constante evolución.

Es decir, que existe una libertad total en la creación y en la apreciación de un mensaje visual, pero cada época, sociedad y pais, segün las condiciones especificas que lo caracterizan, perfila, señala y favorece un determinado conjunto de formas que se reflejan y se corresponden con el resto de las manifestaciones que se materialicen en una imagen visual.

Fuente: elaboración propia. 
El nivel de análisis continúa con el estudio compositivo de la imagen, en el cual se examinó cómo se relacionan los elementos anteriores en la sintaxis y estructura de la imagen. De igual forma en este nivel se incluyen los elementos de escala como lo son la perspectiva, profundidad y proporción: al igual que los elementos que determinan el dinamismo en la imagen como la tensión y el ritmo. Todo esto con la finalidad de ahondar en la composición plástica de la imagen (figura 3).

Uno de los principales puntos a destacar es la escasa existencia de documentos que aborden el estudio de los elementos formales en La gran ola de Kanagawa, son muy pocos los documentos de esta naturaleza y solo hemos identificado uno de cual partimos y es el libro Treinta y seis vistas del monte Fuji del especialista en las estampas ukiyo-e y cultura japonesa David Almazán Tomás (2016); documento el cual tomamos como referencia es punto de partida en la realización del presente trabajo. Se considera primordial mencionar que existen diversas investigaciones alrededor de las estampas ukiyo-e, así como valiosas aportaciones recientes editadas en habla hispana, pero estas investigaciones, no menos importantes suelen centrarse en el contexto histórico, social y político de las ukiyo-e y de la clase social que representaban, siendo parte fundamental para entender la imagen pero no se había continuado con el estudio de los elementos visuales formales dentro de esta manifestación artística. 
ANÁLISIS DE LA IMAGEN (XILOGRÁFICA) Tomado de Propuesta de modelo de análisis de la imagen fotográfica, Descripeión de conceptos contemplados (2004), Marzal Felici.

\section{Nivel compositivo}

\section{Perspectiva:}

Se sabe que Hokusai estudió pintura europea, (Holanda era el úníco pais que podia comercian con Japón en aquel entonces). Se desconoce si Hokusai tomó estudios en especifico de geometría o matemáticas, to que si, es que fue un gran estudioso y observador de la naturaleza, posible razón por la cual La gran ola de En la repecsentación de esta pieza, Hokusai eligió una perspectiva dramática y desproporcionada, de poco uso en aquél periodo, donde la ola es más alta que el monte Fuji.

\section{Ritmo:}

Hablamos de elementos visuales (puntos, linex formas, objetos.) goc se repiten en el copacio de

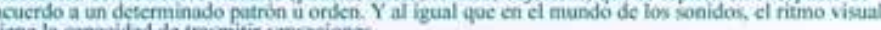
ticne la capacidad de imsmitir sensaciones.

e. dec cla.

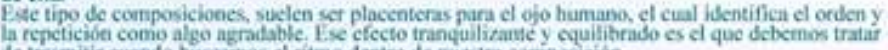
Se trasmitir cuando buscames el ritmo dentro de naestra coriposicion.

Ritmo radial:

Ese tipo de ritmo se crea de modo circular y expansivo alrededor de un puato central. Desde este punto especifico, se va expandiendo y dilatándo en forma de espiral, ondas o circulos

La Gran ola de Kanagawa es la representación en movimiento de un fenómeno nanural que puede expresarse ritmicamente, el ritmo (radial) es representado en forma de espiral conformada con los planos de la ola y completado por la textura de la espuma que configura el semicircula.

Asi mismo el cuerpo y la base de las olas están formados por planos de ritmo similar y contrastados (en forma y color).

\section{Tensión:}

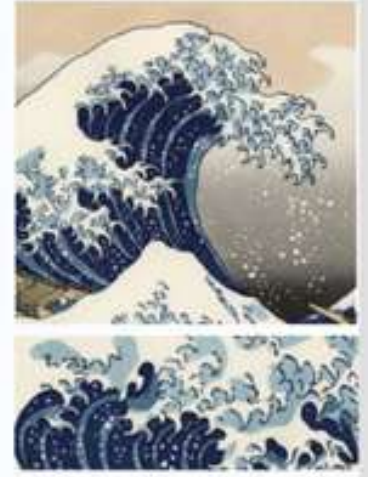

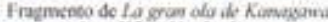
cixteplificacion de ritum

Sa valor para la teoria de la percepeión está en cómo se use en la comunicaciōn visual, es decir, en cómo refuerce el sägnificado, el propósito. la intención y, además, en cómo pueda usane como base para la interpretación y la comprensión. La tensión o la ausencia Ge iensión es el prifter fictor compoxitivo gue podemes usar sinticticamente en nuestra busqued de la alfabetidad visual (Dondis). En primer lugar, el caso en que la tensión (lo inesperado, lo miss imegular, lo complejo, lo inestable) no es lo untico que domina al ojo

La estampa tiene tension respecto a su base y el eje vertical la obra es irregular y compleja.

Proporción:

Las formas adquieren su significado cuando se estructunan dentro de ana composición. Por ese esulta fundamentil onganirar los clementios que forman el conjunto de la imauen de manera equilitrada para obtener un efesio de unidad y orden, asignándole a cada uno de ellos el tarmaño y th phicion accecuados para el fin que nos propongamos

El "protagonista" de la imagen, el monte fuji es representado proporcionalmente a la dimensión de la ola; pues el artista dentro de su imaginario señala la lejania de la montanta por medio de la disminución del tamaño de la misma en comparación a la magnitud ola.

Distribución pesos / Centro de interés:

Una composición informal ( $\sin$ orden en la composición de tipo matemático) dete coordinat sus elementos ulrededor de un centro de interes un area Jonde todos los elementos se originan, cesan interascionan, proporcionando el drama visual sin el cual el discho se convierte en una simple auregación de paries

El centro de interés de la Gran ola de Kanagawa se ubica en la curvatura que forma ta ola. pues es el ârea donde existe movimiento y agitación en la imagen; que a su vez interacciona con el monte Fuji ubicado en la parte central de la composicion, así como en el último plano de la estampa.

Estaticidad / Dinamicidad:

La estampa tiene un diseño radiado basado en la rotación de su centro de referencia.

Otros (composición):

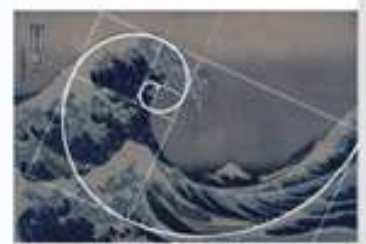

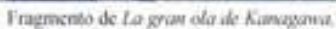
proporcioin inirea

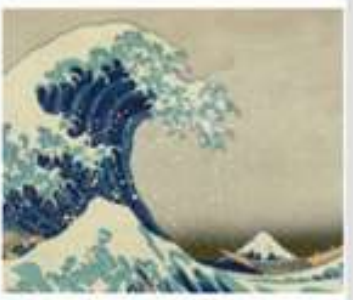

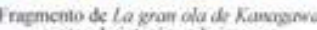
centro de intents en la imxect

La imagen está dividida verticalmente, por un lado, el cielo y por el otro extremo el espacio terrenal que en este caso esta representado por el mar (La gran ola). En la parte representación terrestre, se encuentra la actividad humana, figurada en forma de trabajo, en particular de la pesca, que a su vez se puede interpretar como una lucha. Todo. en conjunto observade por el Fuji (sin perder el protagonisme en esta representación), el cual se puede observar a la distancia.

- Las dos grandes masas ocupan el espacio visual, la violencia de la gran ola se contrapone a la serenidad del fondo vacio, lo que hace recordar al simbolo del yin y yang. El hombre, impotente, lucha entre los dos (lo que puede constituir una referencia al taoistio, pero tambien al budismo)

Fuente: elaboración propia. 
En lo que corresponde a efectuar este trabajo con la propuesta de análisis de la imagen fotográfica del Javier Marzal Felici, se ha podido experimentar y constatar sus bondades en cuanto a estructura y practicidad, en lo relacionado con la realización al que el estudio se refiere, así como su pertinencia no solo en el estudio de la imagen fotográfica de autor como se plantea originalmente el estudio sino en obras artísticas e incluso en estampas xilográficas japonesas, pues la técnica con la que se realizó la imagen, es un dato valioso pero no altera el resto de los rubros a analizar durante el estudio formal de la imagen planteado por el autor.

\section{Conclusiones}

De inicio, cabe considerar que comprende mucho mejor el estudio de La gran ola de Kanagawa si se toma en consideración al conjunto de piezas a la que pertenece. En la serie Treinta y seis vistas del monte Fuji es posible observar una gran diversidad compositiva presente en el uso de encuadres, ritmos, multiplicidad de planos y pluralidad de color.

Regresando al objetivo del presente documento, en lo que corresponde al análisis formal de la imagen de la gran ola de Kanagawa se encontró una imagen de una calidad asombrosa en lo que concierne a su representación. Es una imagen llena de detalle y texturas visuales donde se puede observar la experiencia de un ya consolidado maestro de la ilustración y del grabado con más de 70 años de edad al momento de realizar la obra.

Formalmente La gran ola de Kanagawa es muy detallada. Partiendo del nivel morfológico en el análisis es importante reconocer la calidad y el detalle en la ejecución de la pieza, sin olvidar que es una estampa que tuvo su origen como una ilustración para después ser tallada en una matriz de madera para finalmente serlo color por color. La imagen es de una calidad asombrosa, desde el nivel morfológico es posible distinguir el uso de la línea en la obra como elemento configurador que delimita cada parte ilustrada en el paisaje y a su vez es un elemento expresivo, un trazo delgado continuo y uniforme: una línea tranquila, sublime y apacible en contraste al furor de la ola representada en la imagen.

De igual forma, la presente obra cuenta con una abundante cantidad de planos de formas muy variadas e irregulares que dotan de gran detalle a la composición y que se yuxtaponen para crear algunas zonas iluminadas y otras con sombra para finamente otorgarle dimensión a la obra. La línea y los planos formados en la 
composición dan como resultado la representación de formas orgánicas, figurativas y bidimensionales que resultan en representaciones figurativas del monte Fuji, las barcas y el mar (figura 4).

En lo que corresponde a la representación específica del monte Fuji, sin profundizar en toda la carga significativa (filosófica, religiosa y cultural) que tiene este elemento natural para la cultura japonesa; en la obra La gran ola de Kanagawa está representado de un tamaño menor pero muy detallado, de tal forma que es posible visualizar el pico nevado. Así como, aunque este sea el motivo principal de toda la serie, en la estampa La gran ola de Kanagawa tiene una dimensión menor y está ubicado en el último plano de la composición.

Otras formas visibles en la obra son las barcas, que de igual manera que con el monte Fuji sin profundizar en la función de los mismos son llamados específicamente oshiokuri-bune y son unas pequeñas embarcaciones rápidas que eran empleadas para transportar arroz, pescado o té. A nivel morfológico son la representación de tres barcas, solo una está constituida en su totalidad, las otras dos están ilustradas en una parte y el resto no es visible por la representación del mar. Las embarcaciones están tripuladas, nos permiten ver que cada una lleva a bordo diez pasajeros: ocho remeros y dos más en uno de los extremos de cada embarcación. Finamente por medio de la ilustración de estas embarcaciones se ha estimado la dimensión que tendría la ola en la realidad, al tomar estas pequeñas barcas como referencia de dimensión.

El siguiente elemento corresponde a la ilustración del mar, es el elemento dominante de la composición, representado de forma de una gran ola la cual se extiende y protagoniza toda la escena antes de caer; al ser la ola el elemento que tiene mayor textura visual dentro de toda la ilustración que detalla y otorga volumen en toda la representación. Se pueden observar principalmente tres tipos de texturas visuales: lineal, de planos que crean las luces y sobras en la ola, así como un efecto de profundidad; de tipo puntillismo, la cual representa la espuma de las olas; y una de tipo espiral (en relieve), plano superior de color celeste donde se concentra la mayoría de la espuma.

En lo que corresponde a la nitidez de la imagen e iluminación; es una estampa muy nítida y legible, el observador puede apreciar con facilidad todos los detalles en la imagen. En cuanto a la iluminación, el impresor logra lo que asemeja la representación de la luz natural (al amanecer) la cual permite la aparición de sombras color azul Prusia en las olas las cuales a su vez revelan la aplicación de detalle, el 
color de los elementos y la textura visual en la representación del mar. El paisaje parece representar la luz de una mañana invernal de cielo nublado en tono grisáceo, no obstante, la pieza pertenece a la luminosidad por sus tonos vibrantes.

El contraste en La gran ola de Kanagawa no es solo cromático sino compositivo. Por un lado, en la parte superior se encuentra el cielo en color gris claro y de textura lisa con un ligero degradado que le imprime ligera profundidad al horizonte. En cambio, el mar en la parte inferior de la estampa es un cúmulo de texturas que forman planos y mucho detalle en forma de oleaje y espuma. De igual forma, el contraste cromático entre la profundidad del azul de Prusia y los tintes brillantes en el color amarillo de las barcas.

Ahora bien, en lo que corresponde al elemento cromático, el azul es el color con mayor aparición en la gran Ola de Kanagawa. La estampa mantiene una armonía en colores relacionados por analogía (de tonalidades en azul) que se obtiene por colores contiguos en el círculo cromático que propician a la semejanza del uno con el otro. En una gama cromática fría, puede indicar (además de la representación de la nieve en el cráter del Monte Fuji) que la imagen fue representada durante una temporada invernal y el instante de claridad antes del amanecer.

Según Eva Heller (2004), el color azul es el color de la divinidad, en analogía con el cielo, el color de lo eterno; en sus palabras "La experiencia cotidiana al azul en el color de todo lo que deseamos que permanezca, de todo lo que debe durar eternamente" (p. 23). En la misma tesitura, Heller (2004) lo describe como el color de la ilusión de espacio, dado que, en contraposición con colores cálidos, un color parece más lejano y distante en cuanto más frio es; asegura que "asociamos colores a las distancias porque los colores cambian con la distancia [...] En la lejanía todos los colores parecen turbios y azulados, debido a las capas de aire que los cubren" (p. 24). Incluso un degradado de azul intenso a azul pálido produce un efecto perspectivista: el azul claro queda ópticamente atrás.

A nivel compositivo, algunos de los atributos identificados son ritmo, dimensión, equilibrio, exageración, simetría, realismo/ distorsión, entre otros. La gran ola de Kanagawa posee ritmo, en ella es posible identificar el orden y la repetición en la representación del movimiento de un fenómeno natural que puede expresarse rítmicamente. El ritmo (radial) es representado en forma de espiral conformada con los planos de la ola y completado por la textura de la espuma que configura el semicírculo. 
Por otra parte, la dimensión de los elementos representados en la obra adquiere su significado acorde a su estructuración en de la composición. Es fundamental la organización de los elementos figurativos (cielo, olas, barcas y Fuji) que forman el conjunto de la imagen de manera equilibrada para obtener un efecto de unidad y orden, asignándole a cada uno de ellos el tamaño y la posición adecuados para el fin que el artista se propuso. El "protagonista" de la imagen, el monte Fuji es representado proporcionalmente a la dimensión de la ola; pues el artista dentro de su imaginario señala la lejanía de la montaña por medio de la disminución del tamaño de la misma en comparación a la magnitud ola.

En relación con el equilibrio, la estampa tiene armonía visual que a su vez es representada por medido de contraste de texturas, así como de color. La imagen posee un centro de gravedad a medio camino entre dos pesos; el primero, el peso de la gran ola, el segundo el cielo a la misma proporción que el área en la que está representado el océano.

Por su parte, la estampa cuenta con el atributo de exageración; es evidente la hipérbole en esta pieza, esta tormenta dentro del imaginario del artista es representada con exageración desde las proporciones de la ola en comparación a las dimensiones de las barcas (fuerza). Así mismo se observa tanto la espontaneidad como a su vez la predictibilidad; la espontaneidad está presente por la fuerza, vigor y desborde en la representación de la ola; al igual que predictibilidad pues al observar la obra en su totalidad es sencillo prever o deducir que si completamos la acción representada según la in formación que brinda esta imagen, la acción siguiente será el abatir de la ola sobre las barcas.

En cuanto a la simetría la gran ola de Kanagawa es una obra simétrica pues como se observa en la imagen el área del cielo es casi proporcional al espacio representativo de la ola, solo que la zona del mar es un poco más grande que el cielo; así como además la zona de océano incorpora la representación del monte Fuji que se deja ver entre las olas.

Ahora bien, en relación con la distorsión y el realismo, hasta cierto punto esta imagen cuenta con ambos atributos: el realismo, pues el autor configura la imagen de tal forma que sugiere una representación directamente asociada a lo que vemos desde nuestra experiencia. Es una representación figurativa, pues como espectadores de la obra nos es fácil identificar todos los elementos formales dentro de la composición y fácilmente reconocemos una ola abatiendo unas barcas entre otras situaciones dentro la imagen. Del mismo modo encontramos algunos tintes 
de distorsión como ya lo hemos comentado con anterioridad en el atributo de exageración por ejemplo la representación de la ola e incluso del monte Fuji son notables hipérboles que sobresalen de la totalidad de la composición.

Finalmente, en lo que atañe al nivel compositivo, en esta obra de Hokusai, así como muchas más tienen como característica destacable el uso de una planimetría y ausencia de perspectiva. Asimismo, la información ambiental que debela el artista es a través del uso de efectos de luz y sombras planas (por ejemplo, la luz representada en la espuma del mar y las escasas sombras dentro de las olas de igual forma son representada con el uso de planos en tonos más oscuros).

En suma, cada detalle hasta este punto nos permite observar que es una obra pensada, configurada por un genio estudioso del detalle y de la composición. Que si bien es la representación mental de la interpretación que hace el autor a este paisaje; cada detalle representado ha capturado el gusto de generaciones póstumas de admiradores de esta obra. 


\section{0}

\section{Referencias}

Almazán, D. (Ed.). (2019). Katsushika Hokusai Treinta seis vistas del monte Fuji. Sans Soleil Ediciones.

Almazán, D. (Ed.). (2016). Katsushika Hokusai Cien vistas del monte Fuji. Sans Soleil Ediciones.

García, P. (2013). De los grabados xilográficos ukiyo-e de la Universidad Complutense de Madrid [Presentación de ponencia]. Funciones y prácticas de la escritura: I Congreso de Investigadores Noveles en Ciencias Documentales, Universidad Complutense de Madrid, Madrid, España, 97-102.

García Rodríguez, A. (2005). Cultura popular y grabado en Japón Sig/os XVII A XIX. El Colegio de México. https://doi.org/10.2307/j.ctv3f8qpk

Heller, E. (2004). Psicología del color: Cómo actúan los colores sobre los sentimientos y la razón. Editorial Gustavo Gili.

Marzal, J. (2005). Una propuesta de análisis de la imagen fotográfica mediante la utilización de tecnologías digitales e informacionales. En R. López et al (eds.), El análisis de la imagen fotográfica. Castelló de la Plana. Universitat Jaume I.

Saracho, M., Martín, B., y Gómez, A. (2013) Frank Lloyd Wright \& Hiroshige; de los grabados japoneses al portafolio wasmuth. EGA. Revista de expresión gráfica arquitectónica, 18(22), 204-213. 